\title{
O processo de internacionalização e o ensino e aprendizagem de língua inglesa no contexto de uma universidade estadual
}

DOI: http://dx.doi.org/10.21165/el.v49i1.2530

\author{
Sandra Mari Kaneko Marques' \\ Melissa Alves Baffi Bonvino²
}

\section{Resumo}

A partir de conceitos de internacionalização e proficiência em língua estrangeira, objetivamos, neste artigo, mapear dados sobre os níveis de proficiência obtidos por aprendizes advindos de projetos de ensino de língua inglesa, com financiamento e parcerias externas, que vêm sendo desenvolvidos em uma universidade pública paulista. No âmbito desses projetos, são oferecidos cursos e testes de nivelamento on-line para alunos de graduação, pós-graduação e servidores. Os cursos ocorrem na modalidade online, utilizando a ferramenta de webconferência Zoom. Os professores atuantes em tais cursos são alunos de graduação e pós-graduação em Letras, orientados por especialistas em formação de professores, tecnologias no ensino de línguas e avaliação.

Palavras-chave: internacionalização; proficiência em língua estrangeira; avaliação; língua inglesa.

\footnotetext{
1 Universidade Estadual Paulista "Júlio de Mesquita Filho" (UNESP), Araraquara, São Paulo, Brasil; sandra.kaneko@unesp.br; http://orcid.org/0000-0002-4755-5375

2 Universidade Estadual Paulista "Júlio de Mesquita Filho" (UNESP), São José do Rio Preto, São Paulo, Brasil; melissa.baffi@unesp.br; https://orcid.org/0000-0003-3559-856X
} 


\title{
The internalization process and English language teaching and learning within a state university
}

\begin{abstract}
Based on the concepts of internationalization and foreign language proficiency, in this article, we aim to map the data on proficiency levels of learners who took part in English teaching projects supported by diverse funding sources that have been developed in a public university in São Paulo state. Within these projects, courses and online placement tests are offered to undergraduate and graduate students, as well as for members of the administrative staff. The courses are online (synchronous) in the web conferencing tool Zoom. The teachers in these courses are undergraduate and graduate students in the area of Language and Linguistics and they are supervised by professors from different areas of expertise, such as teachers' education, technology in language teaching and language assessment.
\end{abstract}

Keywords: internationalization; foreign language proficiency; language assessment; English.

\section{Introdução}

Dado o intenso processo de internacionalização das universidades, é notável a necessidade da comunidade acadêmica em aprimorar seus conhecimentos em inglês para participar de programas de mobilidade entre contextos que oportunizam a troca de ideias e saberes, incentivam a produtividade e as parcerias científicas. Nesse sentido, faz-se necessário considerar a questão da proficiência linguística como a capacidade de operacionalizar a competência incluindo o contexto de uso e os objetivos, assim como os exames utilizados para a mensura da proficiência da comunidade acadêmica.

Junto ao desenvolvimento de políticas linguísticas para viabilizar transformações extensivas e norteadoras no ensino e aprendizagem de línguas em contextos acadêmicos com vistas ao processo de internacionalização, é possível observar um aumento no interesse por cursos e programas afins em diversas instituições de ensino superior, especialmente aqueles que envolvem a língua inglesa. Da mesma forma, cresce representativamente a produção de pesquisas e materiais didáticos que possam fundamentar discussões teórico-metodológicas e práticas pedagógicas. Segundo Oliveira (2019), a língua da ciência é predominantemente o inglês, sendo imprescindível para a produção e divulgação de pesquisas. A proficiência em língua inglesa, assim como em outras línguas, torna-se essencial num contexto acadêmico internacionalizado.

O tema deste estudo motiva-se pelo crescente processo de internacionalização e mobilidade em contextos acadêmicos na contemporaneidade e pela necessidade de se 
desenvolver pesquisas que contribuam para o aperfeiçoamento da proficiência em língua inglesa da comunidade interna à universidade. Nesse contexto, serão apresentadas algumas iniciativas que abordam o ensino de língua inglesa, bem como a avaliação de proficiência no âmbito de dois programas de línguas numa universidade multicampus. O Idiomas sem Fronteiras (ISF) é um dos programas e tem como objetivo: "promover ações em prol de uma política linguística para a internacionalização do Ensino Superior Brasileiro, valorizando a formação especializada de professores de línguas estrangeiras ${ }^{3 "}$. O outro programa, intitulado "Língua inglesa na UNESP: internacionalização, formação e transversalidade", é fruto de uma parceria público-privada e seu principal intuito é "melhorar o nível de proficiência em língua inglesa em todos os setores da UNESP (alunos de graduação, pós, docentes e servidores técnico-administrativos) ", de acordo com Pinto (2017, p. 6). Tais incentivos fornecidos por esses programas demonstram a importância de ações voltadas para a internacionalização da instituição, apoiadas por diversas instâncias na universidade.

É sabido que um dos maiores obstáculos para a internacionalização em muitas instituições de ensino superior no contexto brasileiro é a falta de proficiência em línguas, principalmente em língua inglesa (FINARDI; SANTOS; GUIMARÃES, 2016). Tendo como base essa premissa, neste artigo apresentamos um recorte do estudo que tem como objetivo principal mapear os níveis de proficiência em língua inglesa da comunidade acadêmica. Para tanto, traremos algumas concepções do que se entende por globalização, internacionalização do currículo e internacionalização em casa. Posteriormente, discutiremos questões fundamentais no que tange ao conceito de avaliação e proficiência em língua estrangeira, para então, descrevermos os programas e cursos de inglês em desenvolvimento na universidade. Após tal contextualização, apresentamos alguns resultados sobre os níveis de proficiência em língua inglesa da comunidade interna.

\section{Globalização, Internacionalização e Ensino Superior}

Muito tem se discutido sobre o processo de internacionalização das universidades, assim como sobre as ações em prol do desenvolvimento de políticas linguísticas para o ensino e aprendizagem de línguas em contextos acadêmicos na contemporaneidade. Com isso, temos o aumento da necessidade de aprimoramento de conhecimentos em língua inglesa (doravante LI) para participar de programas de mobilidade para incentivar produtividade e parcerias científicas (KENNEDY, 2001). Ao se pensar em internacionalização, o que, normalmente, nos vêm à mente, são mobilidade acadêmica e cooperação internacional. Entretanto, o processo de internacionalização inicia-se no final do século 20, caminhando na mesma direção da globalização, impactando fortemente no sistema educacional em diversos níveis, não apenas no ensino superior.

3 Informações disponíveis em: http://isf.mec.gov.br/historico-botoes/entenda-o-isf. Acesso em: 29 ago. 2019. 
Não há como tratar da internacionalização sem reconhecer a influência da globalização na Educação no cenário mundial, um fator determinante para o processo de internacionalização. Não é possível considerar os dois processos como sinônimos, pois a globalização é um conceito concernente ao alcance global, a internacionalização de práticas, costumes, ideologias, tecnologias etc., como um produto da inter-relação das sociedades (CASTRO; PINEDA, 2016). Dessa maneira, o processo de globalização gera "forte pressão sobre os Estados nacionais para que alinhem suas diretrizes educacionais com os princípios de competitividade e eficiência" (GONZALEZ, 2017, p. 3). Finardi, Santos e Guimarães (2016, p. 234) igualmente distinguem esses dois processos, sendo a globalização definida como "as relações globais baseadas nas operações de mercados livres, é frequentemente vista como um sinônimo da internacionalização do ensino superior, definida como estratégia pela qual as universidades respondem à globalização".

Para Wächter (2000), a globalização se refere a mudanças no ambiente econômico, social, político e cultural, trazidas pela competição global, integração de mercados, avanços nas tecnologias de informação e comunicação e mobilidade. Tais mudanças perpassam os indivíduos, sofrendo suas influências. Já a internacionalização é baseada em ações conscientes sejam elas individuais ou institucionais. Podemos afirmar que a globalização tem mudado as compreensões acerca da internacionalização.

Uma das primeiras definições de internacionalização a conceitua como "o processo de integrar uma dimensão internacional na pesquisa, no ensino e nos serviços do ensino superior 4" (KNIGHT, 1993 apud WÄCHTER, 2000, p. 5, tradução nossa). Wächter (2000) aponta que, por muitos anos, internacionalização e cooperação internacional foram compreendidas como mobilidade acadêmica, especialmente, de alunos. Com base nessas premissas, Morosini e Ustárroz (2016, p. 37) revisam esse conceito e definem o processo de internacionalização como algo muito mais amplo do que a mobilidade e cooperação, envolvendo também o "compartilhamento de descobertas, a transferência de conhecimento, a reconfiguração e a flexibilização dos currículos, a construção da cidadania global, entre outras dimensões".

Já Miho (2017) define internacionalização como processo que atua no ensino superior, que amplia e solidifica as relações entre produção de conhecimento científico e de tecnologia de informação e os mercados internacionais. Frente a tais definições trazidas por esses autores, entendemos que a globalização impulsionou mudanças em diversas esferas da sociedade, entre elas, a Educação. Com isso, o sistema de ensino superior, contexto foco deste trabalho, passou a investir fortemente no processo de internacionalização, visando à preparação de futuros profissionais, por meio do desenvolvimento de qualificações internacionais e competências interculturais para enfrentar desafios não somente locais, mas também globais (MOROSINI; USTÁRROZ, 2016).

4 No original: "The process of integrating an international dimension into research, teaching and services function of higher education". 
Torna-se, portanto, imprescindível discutir o que se entende por currículo internacionalizado e internacionalização em casa. Ao tratarmos de internacionalização, frequentemente, o termo mobilidade surge, provavelmente devido ao fato de que tal termo pode ser facilmente convertido em números e porcentagens como apresentação de resultados. Embora a mobilidade seja uma ação importante no cenário de internacionalização acadêmica, é necessário reconhecer e investir em outros componentes da internacionalização que tenham como foco resultados de aprendizagem internacionalizados de todo o corpo discente de uma instituição e não apenas de uma minoria que participa de programas de mobilidade (WIT; LEASK, 2015; BEELEN; JONES, 2015). Ainda de acordo com os autores (op. cit.), fatores disciplinares, institucionais, locais, nacionais, regionais e globais interagem de diferentes maneiras, podendo facilitar ou não as abordagens voltadas para a internacionalização, incluindo como a aprendizagem é definida e avaliada.

Leask (2015 apud WIT; LEASK, 2015, p. 11, tradução nossa) define currículo internacionalizado como "o processo de incorporação de dimensões internacionais, interculturais e globais no conteúdo curricular assim como nos resultados da aprendizagem, tarefas avaliativas, métodos de ensino e serviços de apoio de um programa de estudo ${ }^{\prime \prime}$. Morosini e Ustárroz (2016) argumentam que o currículo internacionalizado é um meio pelo qual todos os estudantes podem se beneficiar do processo de internacionalização, pois envolve um conjunto de atividades realizadas na própria instituição relacionadas à internacionalização. Assim, compreendemos que um currículo internacionalizado prevê o atendimento de alunos locais e estrangeiros de forma a prepará-los para atuarem em contextos multiculturais e internacionais.

Em um currículo internacionalizado, alguns objetivos devem ser considerados, segundo Nilsson (2000), sendo eles cognitivos e atitudinais. Os objetivos cognitivos são descritos pelo autor como aqueles que visam desenvolver competências internacionais, envolvem o conhecimento de línguas estrangeiras, bem como estudos locais e regionais. Já os objetivos atitudinais envolvem o estímulo ao desenvolvimento da competência intercultural, abordando diferentes dimensões relacionadas aos valores culturais, envolvendo a compreensão e o respeito a diferentes culturas.

Nesse sentido, tem se convencionado chamar essa compreensão e suas consequentes concretizações por meio de ações e atividades, como internacionalização em casa (MOROSINI; USTÁRROZ, 2016). Em consonância com essas autoras, Wächter (2000) conceitua internacionalização em casa simplesmente como qualquer atividade com viés internacional desenvolvida no contexto educacional que não envolva a mobilidade

5 No original: "the process of incorporating international, intercultural and global dimensions into the content of the curriculum as well as the learning outcomes, assessment tasks, teaching methods and support services of a program of study". 
acadêmica. Já Beelen e Jones (2015) afirmam que a internacionalização em casa é um termo conveniente para designar atividades de internacionalização que focam todo o corpo discente. Para os autores, é a integração de dimensões internacionais e interculturais no currículo formal e informal para todo o corpo discente inserido em um contexto doméstico. Assim, para esses autores, a internacionalização do currículo se refere ao currículo em sua totalidade, independentemente de onde ele é ministrado.

Alguns exemplos envolvendo as premissas de internacionalização em casa incluem: tandem presencial entre alunos locais e estrangeiros, COIL (Collaborative Online International Learning) que permite a interação entre alunos locais e estrangeiros por meio de atividades direcionadas envolvendo a colaboração entre diferentes instituições. Esses exemplos podem ainda ser complementados por outras atividades promovidas com assistência de estrangeiros que vivem no país e com indivíduos locais que viveram no exterior ou que de alguma maneira ganharam competências internacionais e interculturais.

Outro pilar teórico que sustenta as discussões trazidas neste artigo se refere à proficiência e avaliação em língua estrangeira, tratados na seção seguinte.

\section{Proficiência e avaliação}

O desenvolvimento e o aprimoramento da proficiência em língua estrangeira, por membros da comunidade acadêmica, têm se apresentado como indispensáveis frente à possibilidade de mobilidade e colaboração científıca. Nesse cenário, o foco incide sobretudo na proficiência em língua inglesa apresentada por alunos, professores e funcionários.

A noção de proficiência tem papel fundamental no processo de ensino, aprendizagem e avaliação (HARSCH, 2017) e é significativa por nortear as tomadas de decisões sobre políticas linguísticas em programas que envolvam o ensino de língua estrangeira, conforme referenciado por Scaramucci (2000), sendo vista como meta e definida em termos de padrões ou objetivos, que podem fornecer dados sobre o desempenho de indivíduos quanto ao êxito do processo de ensino e aprendizagem.

O Conselho da Europa apresenta o conceito de proficiência amplamente aceito, de acordo com Harsch (2017), que diz respeito ao "que alguém pode fazer ou sabe em relação à aplicação do assunto no mundo real" (Council of Europe, 2001, p. 183). Tal conceituação se alinha à de proficiência adotada neste estudo, em que a proficiência se caracteriza como relativa e vinculada à capacidade de uso da competência linguística em um contexto social, segundo Scaramucci (2000), sendo demonstrada no desempenho e na especificidade da situação de uso futuro da língua. 
A proficiência tida como meta, determinada por objetivos, acentua a importância de processos avaliativos de proficiência em língua estrangeira na elaboração e execução de programas de ensino e aprendizagem de uma língua estrangeira, para que seja possível considerar os níveis iniciais e finais de proficiência dos participantes. Portanto, tais objetivos podem ser empregados como critérios para avaliar a proficiência empiricamente, segundo Stern (1983), tendo por foco o desempenho efetivo de um indivíduo ou grupo de indivíduos.

A avaliação da aprendizagem de línguas pode ser considerada um procedimento para que evidências de capacidades gerais ou específicas do desempenho sejam coletadas por meio de tarefas destinadas a fornecer subsídios para previsões sobre o uso dessas capacidades em contextos reais (MCNAMARA, 2000). A utilização de testes para a mensura da proficiência pode oferecer, de acordo com Savignon (1983), um exemplo de comportamento, e baseando-se no desempenho observado (observed performance), obtido em um teste, são feitas inferências sobre as competências subjacentes (underlying competence) mais gerais de um indivíduo, ao desempenhar tarefas similares ou relacionadas, sendo a amostra de comportamento em teste um reflexo verdadeiro da competência subjacente que um teste é designado a avaliar. O progresso de um indivíduo em direção ao desempenho, no entanto, deve ser medido de maneiras consistentes com o construto de proficiência subjacente àquele objetivo. Para esta autora, a proficiência na língua "é" competência comunicativa e deve ser definida e avaliada como tal.

Na próxima seção, apresentamos uma breve descrição dos programas envolvidos neste estudo, bem como dos cursos ministrados e dos testes utilizados para mapear o nível de proficiência dos aprendizes.

\section{Descrição dos Programas e Cursos}

O primeiro programa a ser descrito neste artigo tem sua origem no antigo programa Ciências sem Fronteiras (CsF), criado em 2011 com o intuito de acompanhar os avanços na produção de conhecimento com a globalização e internacionalização, investindo na "consolidação, expansão e internacionalização da ciência e tecnologia, da inovação e da competitividade brasileira por meio do intercâmbio e da mobilidade internacional" ${ }^{\prime}$. Os objetivos eram relevantes e voltados para a internacionalização no contexto acadêmico. Entretanto, como um de seus resultados, evidenciou claramente que muitos alunos em diversas universidades brasileiras não conseguiam comprovar o nível de proficiência necessário, um dos pré-requisitos para participar do programa de mobilidade. A partir dessa problemática, foram credenciados centros aplicadores do exame TOEFL (Test of English as a Foreign Language) em universidades federais, sendo

6 Informações disponíveis em: http://www.cienciasemfronteiras.gov.br/web/csf/o-programa Acesso em: 7 ago. 2018. 
uma das atividades iniciais do Inglês sem Fronteiras, em 2012. Entre os anos 2012 e 20157, foram incorporadas outras línguas estrangeiras ao programa, como espanhol, francês, italiano, alemão, japonês e português para estrangeiros, passando a ser então denominado Programa Idiomas sem Fronteiras (ISF), conforme a portaria normativa n॰ 973/2014 do Ministério da Educação (KANEKO-MARQUES; GARCIA, 2019). Em 2019, o programa sofreu com o contingenciamento da verba destinada ao Ensino Superior, tendo as bolsas de professores e coordenadores (gerais e pedagógicos de inglês) subitamente suspensas. Atualmente, o programa tem se mantido por meio do suporte financeiro das instituições participantes e tem utilizado o sistema de gerenciamento de inscrições e emissão de certificados, vinculado ao Ministério da Educação. As parcerias internacionais e projetos de mobilidade ainda estão vigentes, pois não dependem do governo federal.

O segundo programa, "Língua Inglesa na UNESP: internacionalização, formação e transversalidade", é fruto de uma parceria público-privada que conta com financiamento externo de uma instituição financeira privada. O programa teve início em 2017 e será finalizado em 2021, e tem atuado em diversas linhas por meio de diferentes ações, sendo elas (PINTO, 2017):

- Ação 1: Melhoramento do Nível de Proficiência em Língua Inglesa dos alunos de graduação;

- Ação 2: Treinamento de Inglês para Escritórios de Internacionalização;

- Ação 3: Escrita de Artigos Científicos em Língua Inglesa;

- Ação 4: Expansão do projeto Teletandem Brasil: aprimoramento da língua inglesa e desenvolvimento de projetos de cooperação internacional;

- Ação 5: Melhoria da Infraestrutura dos Centros de Línguas da UNESP para se tornarem Centros Aplicadores de Provas de Língua Inglesa e para Elaboração de cursos presenciais, on-line e Teletandem;

- Ação 6: Busca de Parcerias internas e externas para apoio às propostas elaboradas neste programa.

Os dois programas descritos oferecem cursos on-line de inglês para fins ocupacionais para servidores técnico-administrativos, cursos de inglês para fins acadêmicos para

7 Informações disponíveis em: http://isf.mec.gov.br/programa-isf/historico. Acesso em: 24 ago. 2018. 
alunos de graduação e de pós-graduação e cursos de escrita acadêmica para alunos de pós-graduação. Tais cursos são oferecidos de forma síncrona por meio da ferramenta de webconferência Zoom. Os professores que ministram os cursos são alunos de graduação e pós-graduação na área de Letras, supervisionados por professores especialistas nas áreas de formação de professores, tecnologias no ensino de línguas, inglês acadêmico e avaliação. Reuniões de planejamento de curso, elaboração de material didático e acompanhamento das aulas também são realizadas de forma on-line, uma vez que a equipe se encontra distribuída em três campi em cidades distintas. As leituras e discussões propostas nas reuniões ficam disponibilizadas no ambiente virtual Padlet. Os resultados têm apontado que os alunos desses cursos se mostram satisfeitos com a organização do curso, demonstrando também a importância em se aprender a língua inglesa na contemporaneidade. O curso de escrita acadêmica foi oferecido por uma docente americana, especialista no ensino de inglês para estrangeiros, tendo o acompanhamento de professores-bolsistas e de uma das coordenadoras do programa da universidade. Já os demais cursos voltados para os funcionários e alunos (graduação e pós-graduação) foram ministrados por professores graduados e pós-graduandos da universidade, sob a orientação pedagógica da equipe de coordenadoras, que conta com docentes vinculadas aos cursos de Letras das três unidades universitárias da instituição em questão.

Tendo apresentado, brevemente, os programas e cursos nos quais as informações acerca do nível de proficiência de membros da comunidade interna foram coletadas, trataremos dos resultados na seção seguinte.

\section{Procedimentos metodológicos}

A metodologia deste estudo conta com uma fonte de dados predominantemente descritivos com foco no processo (CRESWEL, 2007; LAKATOS; MARCONI, 2011) que se relacionam com a discussão dos conceitos centrais e correspondentes ao objetivo proposto. Dessa forma, foi realizado um estudo de caráter exploratório a partir dos resultados obtidos por meio da avaliação da proficiência em língua inglesa dos participantes, tendo como ferramenta um teste de nivelamento, o Aptis. Administrado pelo Conselho Britânico ${ }^{8}$, o teste se caracteriza como um sistema de avaliação on-line em que os níveis de proficiência em língua inglesa são classificados de acordo com o Quadro Comum Europeu de Referência para Línguas (QCER), assim como os exames consagrados TOEFL e IELTS, amplamente aceitos em contextos de mobilidade acadêmica. O Aptis não oferece certificação de proficiência reconhecida e válida para fins de mobilidade como os exames de alta relevância, por não particularizar elementos de validade, como administração e supervisão, por exemplo. Esses elementos são de responsabilidade dos candidatos, que são incentivados a utilizar o teste para gerar evidências para o fim a que se destina (O'SULLIVAN, 2012). E, desse modo, o Aptis pode ser considerado uma medida confiável para geração de dados neste estudo, por apresentar alta validade de face na

8 Disponível em: https://www.britishcouncil.org.br/exame/aptis. Acesso em: 24 ago. 2018. 
área de Linguística Aplicada e Avaliação em Língua Estrangeira ao fornecer níveis de proficiência em língua inglesa.

Ressaltamos que a escolha do Aptis para o mapeamento da proficiência da comunidade interna da UNESP se justifica pela análise completa oferecida pelo teste em cada uma das quatro habilidades, combinadas ao componente central de gramática e vocabulário, além de oferecer o nivelamento de proficiência de acordo com o QCER. Outro fator importante que determina a utilização do Aptis é o fato de que os participantes, membros da comunidade interna da universidade, se distribuem por 24 campi. Por ser um exame online, foi possível unificar as aplicações para o levantamento dos níveis de proficiência dos participantes membros da comunidade interna da universidade. Os dados referentes ao nível de proficiência em língua inglesa utilizados para análise, considerados indicadores, foram coletados a partir dos relatórios de cada participante fornecidos pelo Conselho Britânico.

Para a obtenção dos dados referentes à proficiência em língua inglesa, e para que fosse possível conseguir indicadores confiáveis, o exame Aptis foi aplicado aos alunos, membros da comunidade interna inscritos nas ofertas de cursos do programa IsF e do Programa de Língua Inglesa da UNESP nos três últimos semestres. Esses alunos, membros da comunidade acadêmica interna, se caracterizam como participantes deste estudo.

A partir da proposta do projeto de atender a necessidade de aperfeiçoamento da proficiência em língua inglesa, apresentamos, na sequência, o mapeamento dos indicadores de proficiência, realizado ao longo de três semestres de implementação do projeto. Os dados referentes aos níveis de proficiência são utilizados para responder à pergunta de pesquisa "Como se caracterizam os níveis de proficiência obtidos pela comunidade acadêmica interna?". Devido aos limites de espaço deste artigo, apresentamos os dados divididos em três amostras de participantes, com foco nos níveis do QCER.

\section{Análise dos dados}

As amostras aqui apresentadas são referentes a três aplicações do exame Aptis, sendo cada uma equivalente a agrupamentos distintos de participantes da comunidade acadêmica observada. A primeira amostra compreende um grupo amplo e composto por discentes, docentes e servidores técnico-administrativo da UNESP. A segunda envolve alunos vinculados ao projeto de ensino e aprendizagem de língua estrangeira por telecolaboração, o Teletandem (TELLES, 2015, 2006). A terceira amostra compõe-se de um grupo de servidores técnico-administrativos da universidade. 


\section{Amostra 1}

A primeira amostra refere-se aos resultados obtidos por 82 participantes, membros da comunidade interna que realizaram o teste Aptis on-line, por meio do recebimento de senhas enviadas pelo Conselho Britânico. Os participantes realizaram o teste para cada uma das quatro habilidades: compreensão oral, produção escrita, compreensão escrita e produção oral, assim como a parte referente à gramática e vocabulário, o que consideramos como teste completo. Cada participante obteve o nivelamento de proficiência de acordo com o QCER. Apresentamos, portanto, os indicadores obtidos por meio dos dados referentes aos níveis de proficiência em língua inglesa atingidos nesse grupo:

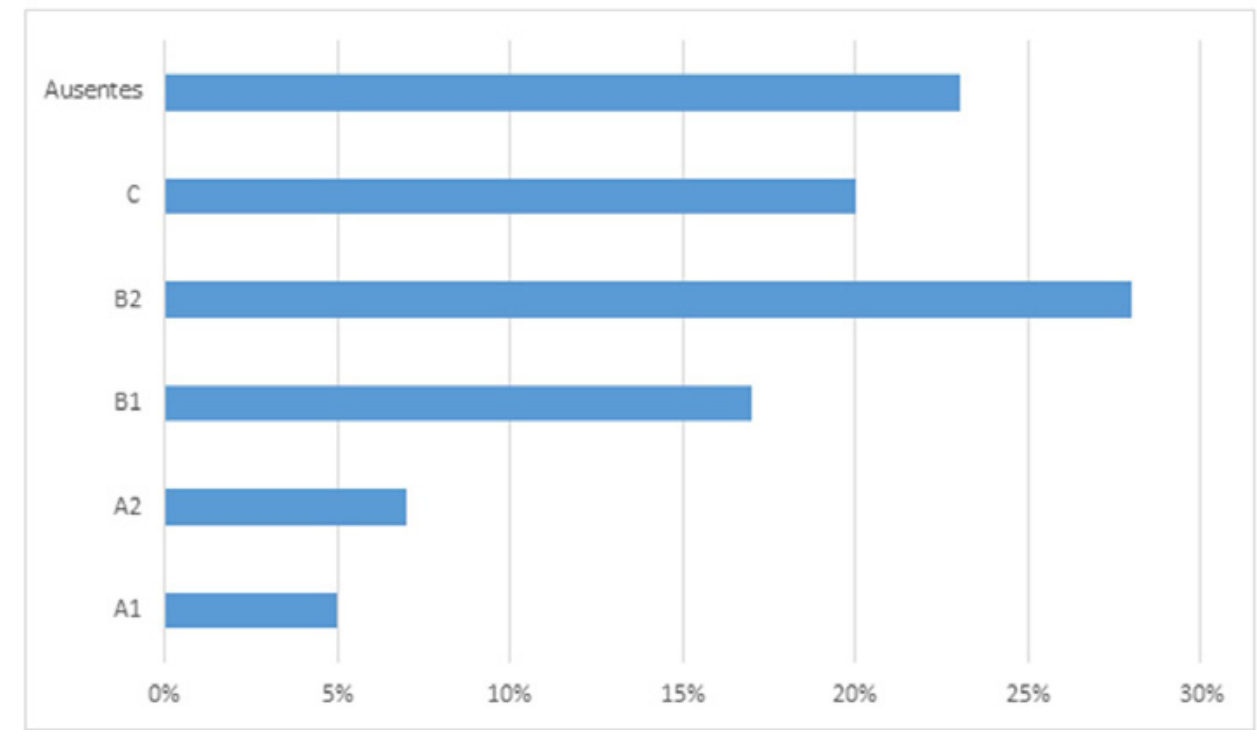

Figura 1. Aptis - amostra 1 - comunidade interna da UNESP

Fonte: Elaboração própria

Os resultados apresentados estão dispostos de acordo com os níveis A1, A2, B1, B2 e C do QCER. É possível observar que uma pequena parcela dos candidatos ao Aptis apresentou nível de proficiência básico, A1 (5\%) e A2 (7\%). A grande maioria se distribui de maneira equilibrada entre os níveis B1 (17\%) e B2 (28\%), que equivalem ao nível intermediário, e o nível C (20\%), que corresponde ao nível avançado de proficiência em língua inglesa. Há ainda que se observar que $23 \%$ dos candidatos inscritos nessa coleta não realizaram o exame e, portanto, constam como ausentes para esta análise.

Durante a fase de implementação do projeto "Língua inglesa na UNESP: internacionalização, formação e transversalidade" foi realizado um mapeamento dos níveis de proficiência da comunidade interna por meio do exame TOEFL. Nessa ocasião, 
os resultados obtidos revelaram que havia uma proporção equilibrada entre os níveis de proficiência apresentados que se concentraram no nível básico A2 com 21,14\% e no nível intermediário B1 com $25,87 \%$ e B2 com 22,47\%, e revelando uma porcentagem baixa para o nível avançado $\mathrm{C}$ com $3,52 \%$.

A partir das ações do projeto, verificamos um aumento nos níveis de proficiência que interessam aos objetivos do estudo, ou seja, os resultados das aplicações do Aptis apresentam maior incidência nos níveis B2 e C, sendo possível constatar um avanço rumo aos níveis superiores de proficiência apresentados por participantes. Os níveis básico superior (A2) e intermediário (B1) apresentam queda nos índices, corroborando o aumento nos níveis seguintes do QCER. A incidência no nível básico aumentou com este mapeamento, mas ainda é bem inferior à proporção de aumento observada nos níveis mais altos. A próxima figura ilustra esses dados:

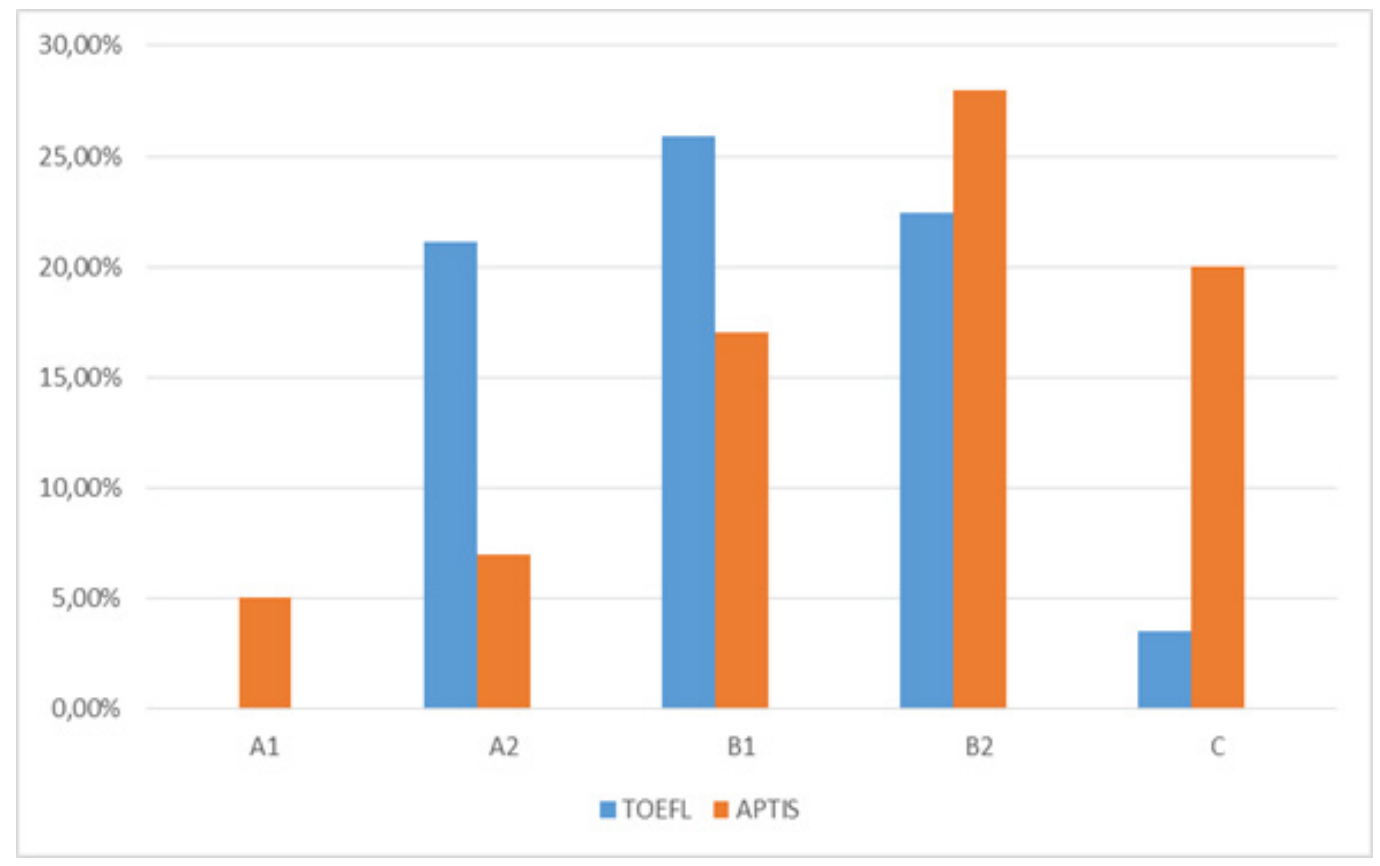

Figura 2. Comparação de dados obtidos por amostras da comunidade interna em exames

Fonte: Elaboração própria 


\section{Amostra 2}

Os indicadores dessa amostra se referem aos resultados de 70 testes Aptis oferecidos a alunos que fazem parte do projeto Teletandem. Dentre os 70, apenas 44 alunos realizaram o teste completo. Os dados correspondem aos níveis de proficiência em língua inglesa obtidos por esses participantes e alinhados de acordo com o QCER. Dessa forma, o gráfico que segue apresenta os indicadores obtidos e considerados como a segunda amostra:

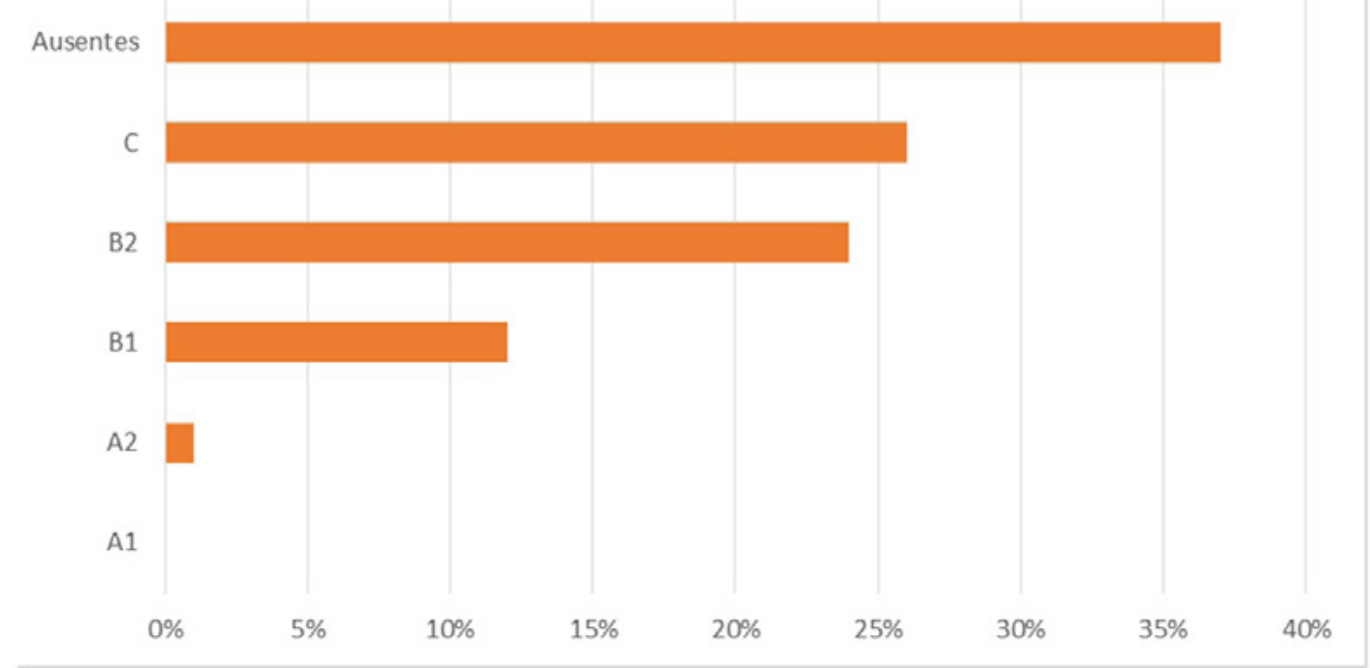

Figura 3. Aptis - amostra 2 - projeto Teletandem

Fonte: Elaboração própria

Foi possível observar que a parcela de alunos candidatos ao exame que apresentaram nível de proficiência básico, ou iniciante, é praticamente nula, pois nenhum aluno obteve o nível A1 (0\%) e apenas 1 aluno se classificou como A2 (1\%). No que se refere ao nível intermediário ou independente conforme o QCER, os alunos que se classificaram com o nível B1 correspondem a apenas 12\%, índice inferior ao do mapeamento anterior, que foi de $17 \%$.

A grande maioria desses alunos se concentra entre os níveis B2, que corresponde ao nível intermediário superior; e C, ao nível avançado de proficiência em língua inglesa. Os dados revelam que $24 \%$ obtiveram o nível B2, um percentual menor do que na primeira aplicação do exame. Já os alunos que conseguiram alcançar o nível C correspondem a $26 \%$, o que revela um aumento de $6 \%$ neste nível de proficiência em relação à análise realizada no primeiro semestre. 


\section{Amostra 3}

Composta por servidores técnico-administrativos matriculados na oferta de cursos vigente no terceiro semestre, a terceira amostra teve o objetivo de mapear os níveis de proficiência desse segmento da universidade. No entanto, dos inscritos, apenas metade dos candidatos realizou o teste de maneira completa. Os dados se distribuem conforme a figura abaixo:

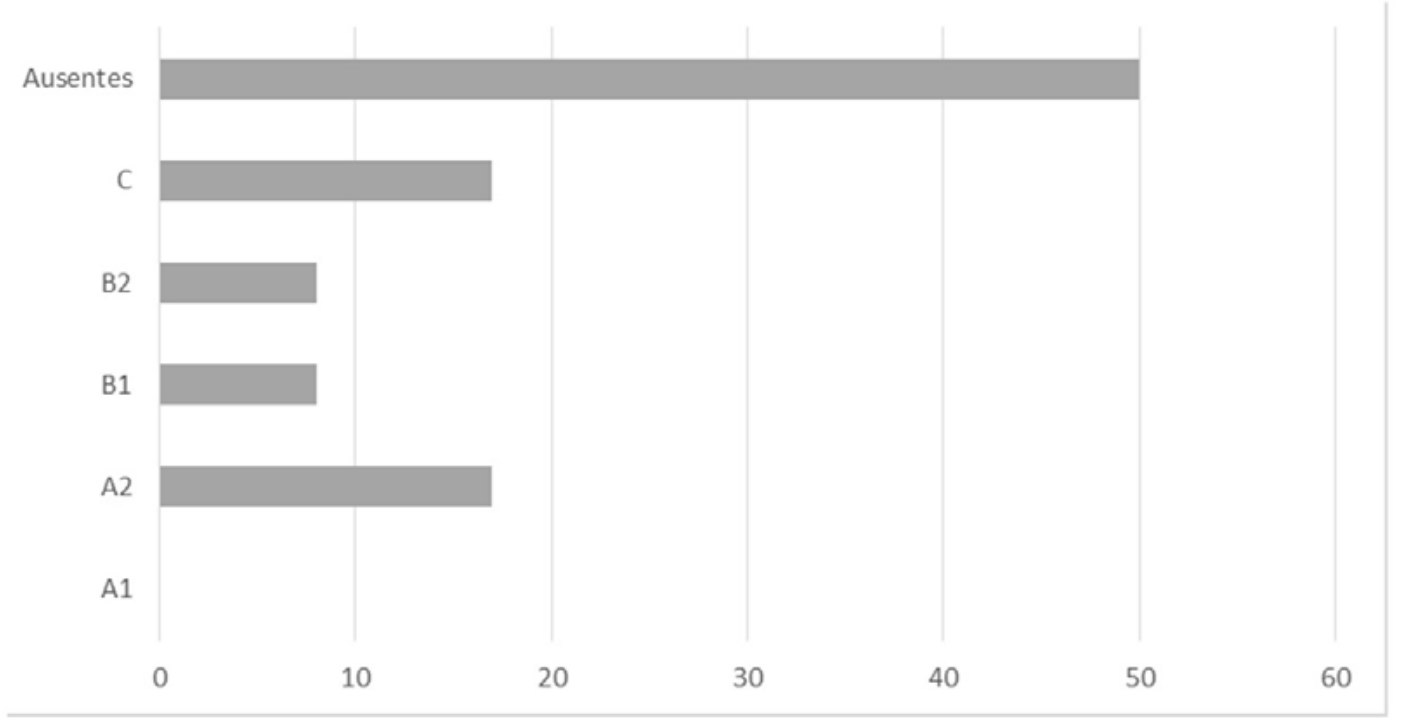

Figura 4. Aptis $3^{\mathrm{a}}$ amostra - Servidores técnico-administrativos UNESP

Fonte: Elaboração própria

Ao considerarmos os dados em um resumo das três amostras, observamos que as amostras 1 e 2 (Aptis 1 e Aptis 2) se distribuem uniformemente entre os níveis de proficiência, com uma concentração harmônica e ascendente nos níveis A1, A2, B1, B2 e C. A terceira amostra (Aptis 3) apresenta a maior parte de participantes concentrada nos níveis A2 (básico) e C (avançado). O gráfico a seguir ilustra essa distribuição: 


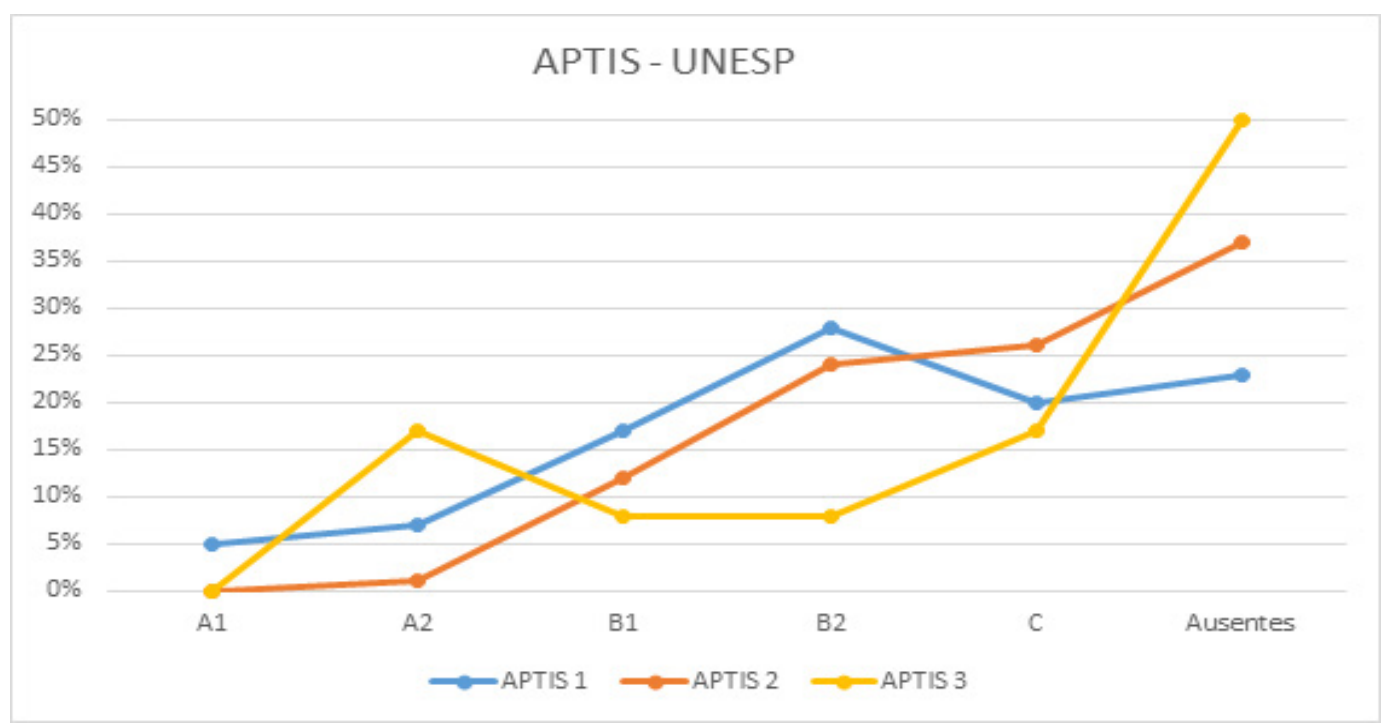

Figura 5. Resumo das três amostras de aplicações - Aptis/UNESP

Fonte: Elaboração própria

Portanto, e de maneira geral, é possível observar que as amostras de candidatos ao exame, compostas por membros da comunidade interna que realizaram os cursos oferecidos, se distribui entre os níveis B2 e C, que correspondem ao nível intermediário e avançado do QCER, respectivamente. Considerando-se ainda que, nas três amostras, $23 \%$ se refere aos ausentes na aplicação do exame, observamos que 48\% desses participantes estão nos níveis intermediário e avançado do QCER (17\% B, 28\% B2 e 20\% C), sendo que apenas 12\% se classifica como nível básico (5\% A1 e 7\% A2).

Os indicadores obtidos para o mapeamento do nível de proficiência deste estudo fornecem dados sobre o desempenho dos participantes quanto ao êxito do processo de ensino e aprendizagem, conforme Scaramucci (2000). Com base nos dados apresentados e considerando a proficiência caracterizada como meta, determinada por objetivo, vinculada à capacidade de uso da competência linguística em um contexto, segundo Scaramucci (2000), e demonstrada no desempenho e na especificidade da situação de uso futuro da língua, inferimos que os processos avaliativos de proficiência como parte de programas de ensino e aprendizagem de uma língua estrangeira permitem que sejam considerados os níveis de proficiência dos participantes como critérios para avaliar a proficiência empiricamente, de acordo com Stern (1983), tendo o desempenho efetivo de um indivíduo ou grupo de indivíduos como foco. 


\section{Considerações finais}

Os níveis de proficiência mapeados por meio da aplicação de testes Aptis forneceram dados a respeito da comunidade acadêmica participante dos programas de mobilidade da universidade que vão ao encontro das questões discutidas sobre o processo de internacionalização. De modo geral, com base nos dados acerca do nível de proficiência da comunidade interna da universidade, notamos que ao longo de três semestres de cursos e coleta, o nível de proficiência dos aprendizes participantes dos programas IsF e Língua Inglesa na UNESP em sua maioria se encontra no nível intermediário. Para as próximas etapas, procuraremos diminuir o número de candidatos ausentes, que não realizaram a prova, por meio de ações de divulgação sobre a importância do teste e do conhecimento em língua inglesa. Além disso, temos como intuito comparar dados de aprendizes que realizaram o teste nos últimos três semestres e que, igualmente, participaram de cursos oferecidos pelos dois programas de ensino de língua inglesa, aqui mencionados, para que possamos aferir o nível de proficiência desses aprendizes após a realização dos cursos.

É notável o reconhecimento da relevância da proficiência em língua inglesa num cenário de internacionalização nos contextos acadêmicos. O oferecimento de cursos de inglês na universidade permite não somente atender requisitos necessários para aqueles interessados em mobilidade acadêmica, mas também se configura como uma ação de internacionalização em casa, ou seja, procura atender a comunidade interna como um todo.

\section{REFERÊNCIAS}

BEELEN, J.; JONES, E. Europe Calling: a new definition for internationalization at home. International Higher Education, Boston, n. 83, p. 12-13, dez. 2015.

CASTRO, W. R. A.; PINEDA, R. E. G. Educación y globalización: una visión crítica. Revista Civilizar Ciencias Sociales y Humanas, Bogotá, v. 16, n. 30, p. 191-206, 2016.

CRESWELL, J. W. Projeto de pesquisa: métodos qualitativo, quantitativo e misto. 2. ed. Porto Alegre: Artmed, 2007.

FINARDI, K.; SANTOS, J.; GUIMARÃES, F. A relação entre línguas estrangeiras e o processo de internacionalização: evidências da coordenação de letramento internacional de uma universidade federal. Interfaces Brasil/Canadá, Canoas, v. 16, n. 1, p. 233-255, 2016.

HARSCH, C. Proficiency. ELT Journal, Oxford, v. 71, n. 2, p. 250-253, 2017. 
GONZALEZ, N. F. La lucha simbólica por la educación en la globalización neoliberal. Revista Brasileira de Educação, Rio de Janeiro, v. 22, n. 71, p. 1-23, 2017.

KANEKO-MARQUES, S. M.; GARCIA, D. N. M. Implementação do programa idiomas sem fronteiras na UNESP. Estudos Linguísticos (São Paulo. 1978), São José do Rio Preto, v. 48, n. 1, p. 242-261, 2019.

KENNEDY, C. Language use, language planning and EAP. In: FLOWERDEW, J.; PEACOCK, M. (ed.). Research perspectives on English for Academic Purposes. Cambridge University Press: Cambridge, 2001. p. 25-41.

LAKATOS, E. M.; MARCONI, M. A. Fundamentos de Metodologia Científica. 5. ed. São Paulo: Atlas, 2003.

MCNAMARA, T. Language testing. Oxford: OUP, 2000.

MIHO, S. R. G. Internacionalização, testes de proficiência e formação de professores. In: Congresso Latino-Americano de Formação de Professores de Línguas, 6, 2016. Londrina, Anais.... Londrina: UEL, 2017. p. 812-824.

MOROSINI, M.; USTÁRROZ, E. Impactos da internacionalização da educação superior: construindo a cidadania global por meio do currículo globalizado e das competências interculturais. Em Aberto, Brasília, v. 29, n. 97, p. 35-46, 2016.

NILSSON, B. Internationalising the curriculum. Internationalisation at Home. A Position Paper. Amsterdã: European Association for International Education (EAIE), 2000. p. 21-27.

OLIVEIRA, S. S. A Língua da ciência. Pesquisa FAPESP, São Paulo, ano 20, n. 282, p. 96-97, 2019 .

O'SULLIVAN, B. Aptis test development approach. London, UK: British Council, 2012.

PINTO, P. T. Língua inglesa na UNESP: internacionalização, formação e transversalidade. Projeto de Pesquisa, São José do Rio Preto, 2017.

SAVIGNON, S. J. Communicative competence: theory and classroom practice texts and contexts in second language learning. USA: Addison Wesley Publishing Company, 1983. 
SCARAMUCCI, M. V. R. Proficiência em LE: considerações terminológicas e conceituais. Trabalhos em Linguística Aplicada, Campinas, v. 36, p. 16-20, 2000.

STERN, H. H. Fundamental concepts of language teaching. Oxford: OUP. 1983.

TELLES, J. A. Teletandem and performativity. Revista Brasileira de Linguística Aplicada, v. 15, n. 1, p. 1-30. 2015. Disponível em: https://www.scielo.br/scielo.php?script=sci_ arttext\&pid=S1984-63982015000100001. Acesso em: 02 jan. 2019.

TELLES, J. A. Projeto Teletandem Brasil: Línguas Estrangeiras para Todos - Ensinando e Aprendendo línguas estrangeiras in-tandem via MSN Messenger. Assi: Faculdade de Ciências e Letras, UNESP. 2006. Disponível em: http://www.teletandembrasil.org/site/ docs/TELETANDEM_BRASIL_completo.pdf. Acesso em: 02 jan. 2019.

WÄCHTER, B. Internationalization at home: the context. In: CROWTHER, P.; JORIS, M.; OTTEN, M.; NILSSON, B.; TEEKENS, H.; WÄCHTER, B. Internationalisation at home. A position paper. Amsterdã: European Association for International Education (EAIE), 2000. p. 5-13.

WIT, H.; LEASK, B. Internationalization, the curriculum, and the disciplines. International higher education, Boston, n. 83, p. 10-12, 2015. 